\title{
RESEARCH OF VIBROACOUSTIC DISTURBANCES INFLUENCE ON THE SHOCK WAVE DETECTION PROCESS
}

\author{
S. Grzywiński *
}

\begin{abstract}
The attention was focused on determining the parameters of disturbances affecting the process of detecting and determining the coordinates of artillery projectiles flying at supersonic speeds. Real conditions of shock wave measurement in the form of strong vibroacoustic disturbances were taken into account. The main emphasis was placed on characterizing and studying vibroacoustic disturbances and their impact on projectile detection. The article presents the research of vibroacoustic disturbances influenceon the shock wave detection process conducted by acoustic locator mounted on the UAV (Unmanned Aerial Vehicle).
\end{abstract}

Keywords: acoustic location, vibroacoustic disturbances, detection, signal to noise ratio

\section{Introduction}

In the last decade, many devices have been created for acoustic detection, classification and determination of coordinates of fire stations, as well as the basic observation object which is an artillery projectile. The devices used for this purpose are called acoustic locators. Their working rules are based on information contained in the shock wave generated by the projectile at supersonic speed. Then a characteristic set of pressure waves is created, which propagates in space, moving along with the projectile. The task of detecting and determining projectile coordinates is carried out on the basis of acoustic signals recorded by the sensor system, using amplitude and time signatures, as well as knowledge of the shape and amplitude-frequency characteristics of the disturbances caused by projectile movement [1]. One of the possible solutions that significantly increase the operational capabilities of the acoustic location system designed to detect and determine the coordinates of artillery projectiles is shown on Fig. 1. System was developed at the Military University of Technology and was also tested in combat conditions. The concept of the acoustic location system was placed on the wing of the unmanned aerial vehicle - UAV. Due to the fact that currently there are more efficient hardware and algorithmic methods of detection, location, recognition and classification of objects that constitute a source of sound waves, the proposed solution is an important stage in the construction of acoustic location systems for artillery projectiles.

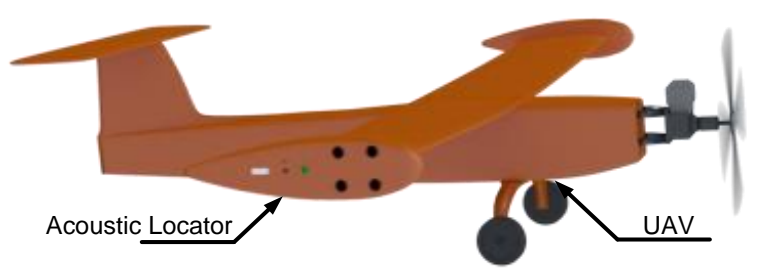

Fig.1. Concept of acoustic locator

Stanisław Grzywiński, PhD.: Faculty of Mechatronics \& Aerospace, Military University of Technology, Urbanowicza 2, 00-908 Warsaw, PL, stanislaw.grzywinski@wat.edu.pl 
The vibroacoustic interference research has shown that the acoustic locator works in conditions of strong disturbances, the energy of which is concentrated in the band of shock wave signals generated by artillery projectiles moving at supersonic speeds. For this reason, it is necessary to conduct research on the impact of interference on the projectile detection process. The author's program, Vibroacoustic Disturbances Model (VDM), which generates signals based on mathematical equations describing vibration phenomena and vibroacoustic noise as well as signals recorded by a multi-channel recorder during disturbance research, was developed [2].

\section{Simulation and experimental research}

The aim of research is to determine the impact of vibroacoustic disturbance on the effectiveness of the projectile detection process. Testing in the combat conditions the possibility of correct detection of artillery projectiles using the acoustic location system located on the UAV with the participation of real vibroacoustic disturbances is difficult to perform, because it requires participation of combat troops on selected artillery equipment in the conditions of training ground. Therefore, the research was carried out indirectly basing on the knowledge of the shock wave parameters for the tested projectiles and the disturbance parameters. Digital signals of shock wave and disturbances were generated using simulation software, based on proprietary program modules: Shock Wave Model (SWM), Model of Sensitivity Aperture (MSA) and Vibrocoustic Disturbance Model (VDM). The research was divided into two stages. In the first one, a detailed analysis of the impact of vibroacutic disturbances on the shock wave detection process using computer simulation methods was made. The tests used the recorded disturbances for UAV occurring under real conditions, for parameters:

- maximum engine speed $n_{o}=6300 \mathrm{rpm}$;

- sound pressure level $135 \mathrm{~dB}$;

- cruising speed of UAV $140 \mathrm{~km} / \mathrm{h}$.

The following weather conditions were adopted:

- $\quad$ air temperature $T_{\mathrm{atm}}=20^{\circ} \mathrm{C}$;

- atmospheric pressure $P_{\mathrm{atm}}=1013.25 \mathrm{hPa}$;

- air density $\rho=1.225 \cdot 10^{-3} \mathrm{~g} / \mathrm{cm}^{3}$;

- air humidity $h_{\mathrm{r}}=70 \%$;

- wind speed in gusts up to $2 \mathrm{~m} / \mathrm{s}$.

The developed simulation model was used to analyze signal parameters and in particular the signal to noise ratio for the phonic shock wave signal on the background of disturbances. The simulation assumes the following signal processing model:

$$
x\left(t, \tau, \Theta_{\mathrm{s}}, \Theta_{\mathrm{z}}\right)=p(t-\tau) * h\left(t, \Theta_{\mathrm{s}}\right)+z(t) * h\left(t, \Theta_{\mathrm{z}}\right)+n(t)
$$

where:

$p(t-\tau) \quad$ - a shock wave signal delayed by $\tau \in\left\langle 0, T_{\mathrm{pz}}\right\rangle$;

$T_{\mathrm{pz}} \quad$ - a period of vibroacoustic disturbances;

$z(t) \quad$ - vibroacoustic interference;

$h\left(t, \Theta_{\mathrm{S}}\right) \quad$ - microphonic impulse response for the angle $\Theta_{\mathrm{S}}$ of wave propagation;

$h\left(t, \Theta_{\mathrm{z}}\right)$ - microphonic impulse response for the angle $\Theta_{\mathrm{z}}$ of interference propagation;

$n(t) \quad$ - microphone own noise.

In the conducted simulation, a shock wave signal was delayed by $\tau$ in relation to the interference signal. The process of the simulation is illustrated in Fig. 2. The tests were carried out for the following conditions: the distance of the projectile from the aperture of the acoustic locator sensors $y_{p} \in\langle 1,30\rangle$ $[\mathrm{m}]$ and the angle of propagation of the $\theta \in\left\langle 0^{\circ}, 90^{\circ}\right\rangle$ disturbance. 


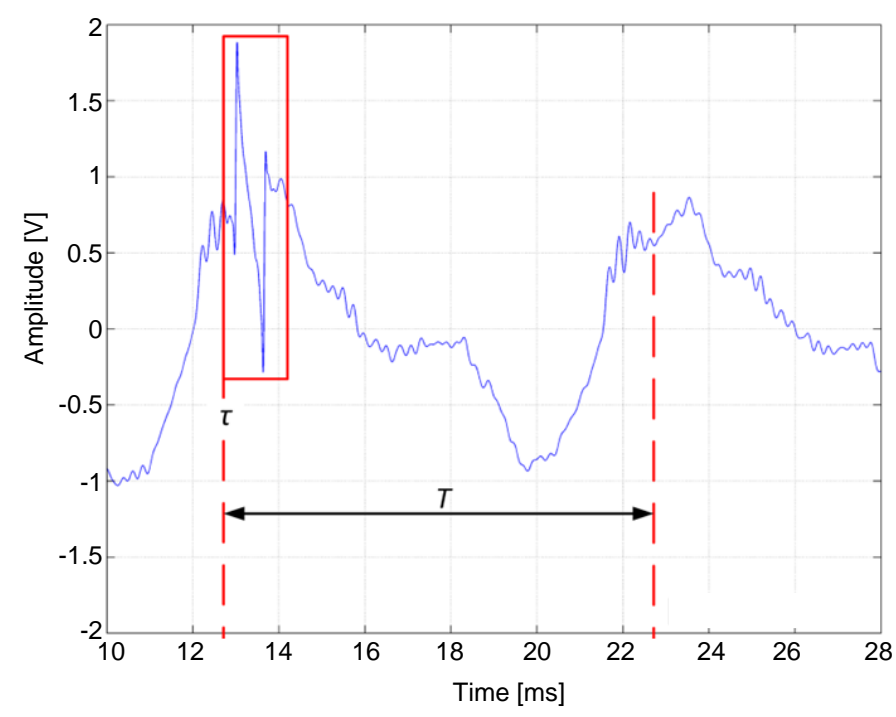

Fig.2. Sequence and simulation conditions

Figure 3 presents the determined values of the signal to noise ratio for the signals $x(t)$ generated by the $23 \mathrm{~mm}$ caliber projectile on $y_{p}$ - its flight distance from the measurement aperture equal to 30 meters. On the axes of the diagrams the direction $\theta$, the delay $\tau$ and the value of the signal to noise ratio, are marked with colors. The tests also include the amplitude limitation of microphones at $160 \mathrm{~dB}$.

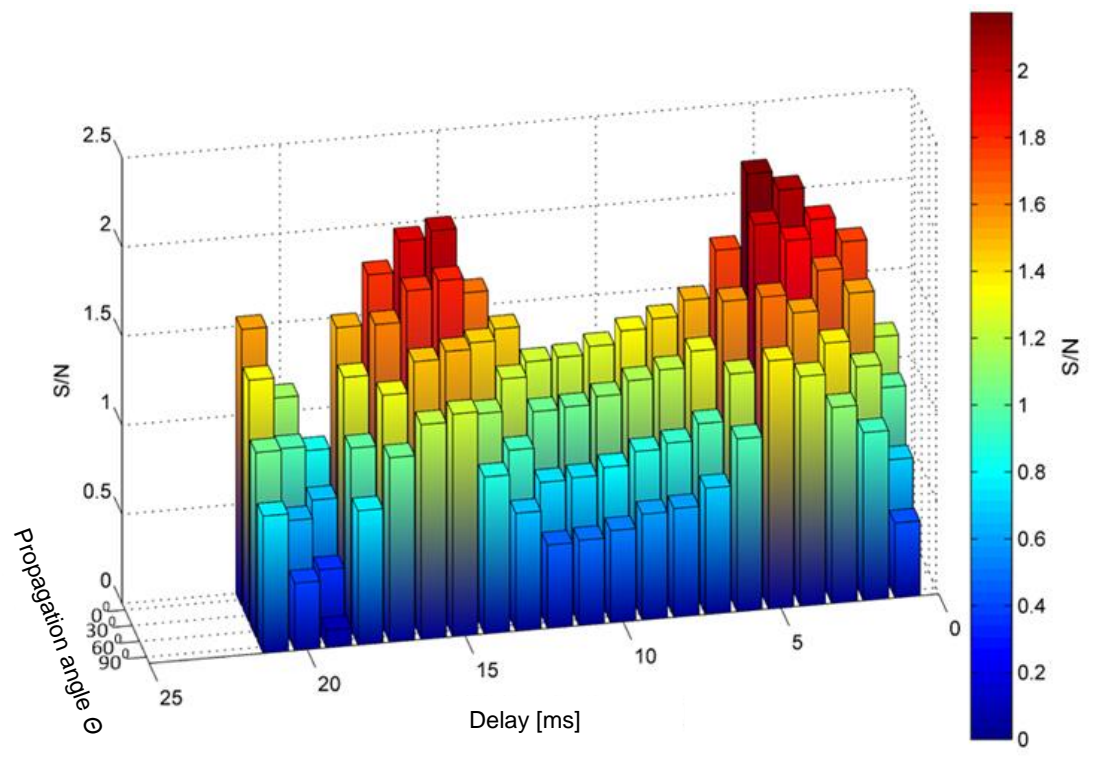

Fig.3. Signal to noise ratio diagram for a $23 \mathrm{~mm}$ caliber projectile at distance $y_{p}=30 \mathrm{~m}$

In the second stage of the research, the source of the signal was an arbitrary generator, which was programmed to generate the signals obtained in the simulation. The generator's signal output is directly connected to amplifier and next to loudspeaker, which allows to generate signals with proper sound pressure level. Amplifier circuits ware designed as adjustable to provide more functional possibilities, but basically it was used to ensure proper amplitude for loudspeaker unit. Sensors of the acoustic locator are marked as M1-M4. The measurement scheme of the station is shown in Figure 4. The purpose of this research was to verify the correctness of analogue processing circuits, matched filters and projectile detection algorithms implemented in the signal processor [3]. 


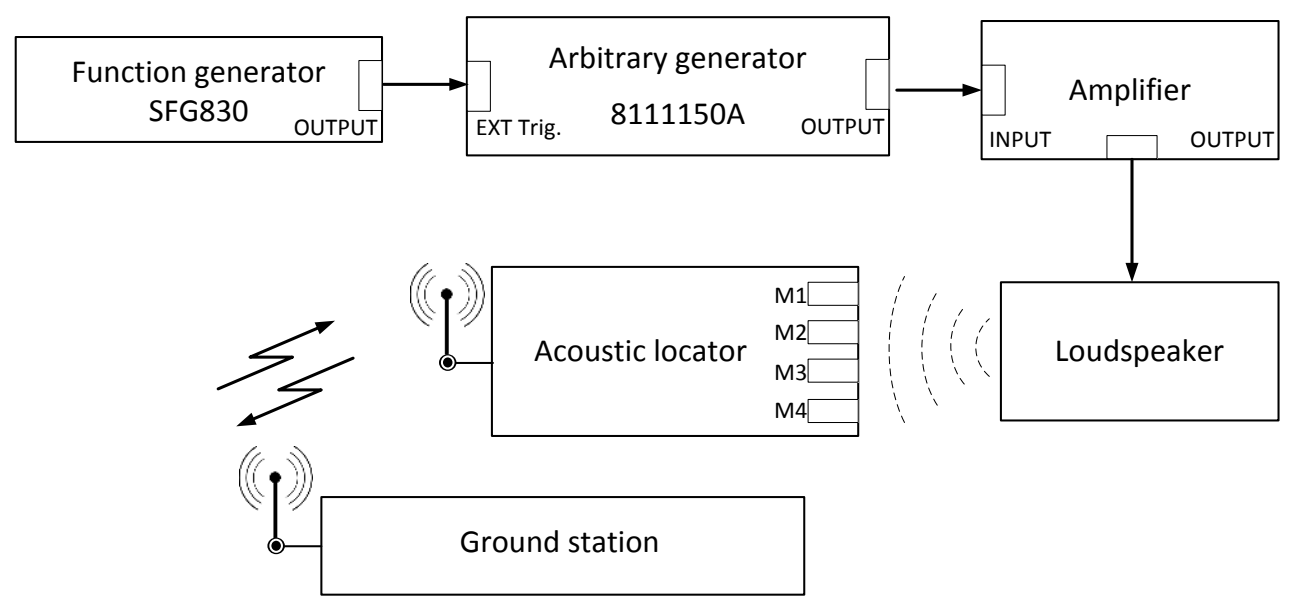

Fig.4. Stand for generation and interference research

In the research, the plane formed by the microphone diaphragms was set perpendicular to the loudspeaker column. The use of an arbitrary generator allowed for the generation of a signal based on the experimental noise signals recorded during UAV flights. Based on the obtained results, it can be concluded that the dynamic range of sound pressure levels at the entry of acoustic locator measuring sensors is more than $30 \mathrm{~dB}$ for $y_{\mathrm{p}} \in\langle 1,30\rangle$ meters and can range from less than $163 \mathrm{~dB}$ to $130 \mathrm{~dB}$. In addition, by taking out the shock wave amplitude detection and the signal to noise $\geq 1$ limit ratio, then for the $23 \mathrm{~mm}$ caliber projectiles we receive the following detection capabilities:

- at a distance of $y_{\mathrm{p}}=10 \mathrm{~m}$ approx. $99 \%$;

- at a distance of $y_{\mathrm{p}}=20 \mathrm{~m}$ approx. $77 \%$;

- at a distance of $y_{\mathrm{p}}=30 \mathrm{~m}$ approx. $40 \%$.

\section{Conclusions}

The experimental tests carried out allowed to determine the impact of vibroacoustic disturbances on the shock wave detection process. In addition, the developed stands enable comprehensive testing of projectile detection methods, including signal processing parameters and interference effects. The obtained simulation results were used to assess the locator detection capabilities. Based on the conducted tests, it was found that the acoustic locator works under strong vibroacoustic disturbances, the power of which is concentrated in the shock wave band. Their presence limits the detection of $23 \mathrm{~mm}$ projectiles above the distance of about $25 \mathrm{~m}$, i.e. the distance of their flow from the aperture formed by acoustic locator measuring sensors. For this distance, a $50 \%$ probability of correct projectile detection is recorded.

\section{References}

Grzywiński S., Żygadło S. 2018. "Design of a remote, multi-channel signal recorder". Mechanic, No. 7/2016: 700701.

Grzywiński S., Żygadło S. 2018. "Experimental research of the power supply source parameters for sensors in project proximity". Proceedings of the 24th International Conference - Engineering Mechanics (EM 2018), ISBN 978-80-214-5497-2, Engineering Mechanics, ACAD SCI Czech Republic 2018, Pages: 114-117.

Pietrasieński J., Grzywiński S. 2012. "Program implementation of an integrated platform for passive location in terms of acoustic networks". Mechanic, No. 07/2012: 705-716.

Daigle GA 1979. "Effects of Atmospheric Turbulence on the Waves Above a Finite Impedance Boundary". JASA 65 (1): 45-49.

McCoy RL 1981. "MC DRAG - A Computer Program for Estimating the Drag Coefficients of Projectiles". Ballistic Research Laboratory.

Pietrasieński J., Grzywiński S., Rodzik D., Miernik J. 2017. "Proving Ground Testing of an Anti-Aircraft Artillery Evaluation System ", Problemy Mechatroniki. Uzbrojenie, lotnictwo, inżynieria bezpieczeństwa, No. 8/2017. 